\title{
Development of CAD System for Gauge based on UG Xue-Bin LIU ${ }^{1},{ }^{*}$, Hai-Li JIA ${ }^{1}$, San-Peng DENG ${ }^{1}$ and Chong-Ning $\mathrm{LI}^{1}$ \\ ${ }^{1}$ Tianjin Key Laboratory of High Speed Cutting \&Precision Machining(TUTE), Tianjin University of Technology and Education, Tianjin, China, 300222 \\ *ewinding@163.com
}

Keywords: Gauge CAD, UG, Gauge design.

\begin{abstract}
In this paper, the structure of CAD system for gauge has been established. By creating parameters model of gauge, smooth limit gauge is developed and designed using the computer aided design calculations in the environment of VC6.0 and UG NX 6.0, in order to improve the gauge design efficiency, the use of parametric technology, by constructing a parametric volume and scale, to establish ways gauge parameter database by the size of drive technology achieve rapid design of the overall gauge.
\end{abstract}

\section{Introduction}

In machinery manufacturing, the shaft diameter of the workpiece, the aperture meets the technical requirements, can be smooth limit gauge for testing. Smooth limit gauge is no specific test tool scale is to facilitate the inspection of product quality and design system to do, cheaper than using a universal measuring instrument test time and effort. Only the parts for testing a gauge within the acceptable size range, but can not obtain specific numerical part specific size, shape and position errors. In the design of the gauge, designers need to consult gauge design parameters, and a lot of calculations, a larger workload, and sometimes man-made calculation errors. To this end, developed and designed using the computer to smooth limit gauge aided design calculations, in order to improve the gauge design efficiency, the use of parametric technology, by constructing a parametric volume and scale, to establish ways gauge parameter database by the size of drive technology achieve rapid design of the overall gauge.

\section{The Overall Structure of the Gauge CAD System}

On the UG platform, using the seconded development of UG Open, C / S structure which has two layers are adopted, namely the client layer and the data layer. The client layer mainly completes the storage of the gauge information, deleting the gauge information and the parameterization modelling of the gauge. The data layer uses the Access database, mainly used to store the gauge data information, including gauge dimension, gauge tolerances, gauge parameters, to provide data support for the customer layer. The overall structure of the gauge CAD system is shown on the figure 1 shows. 


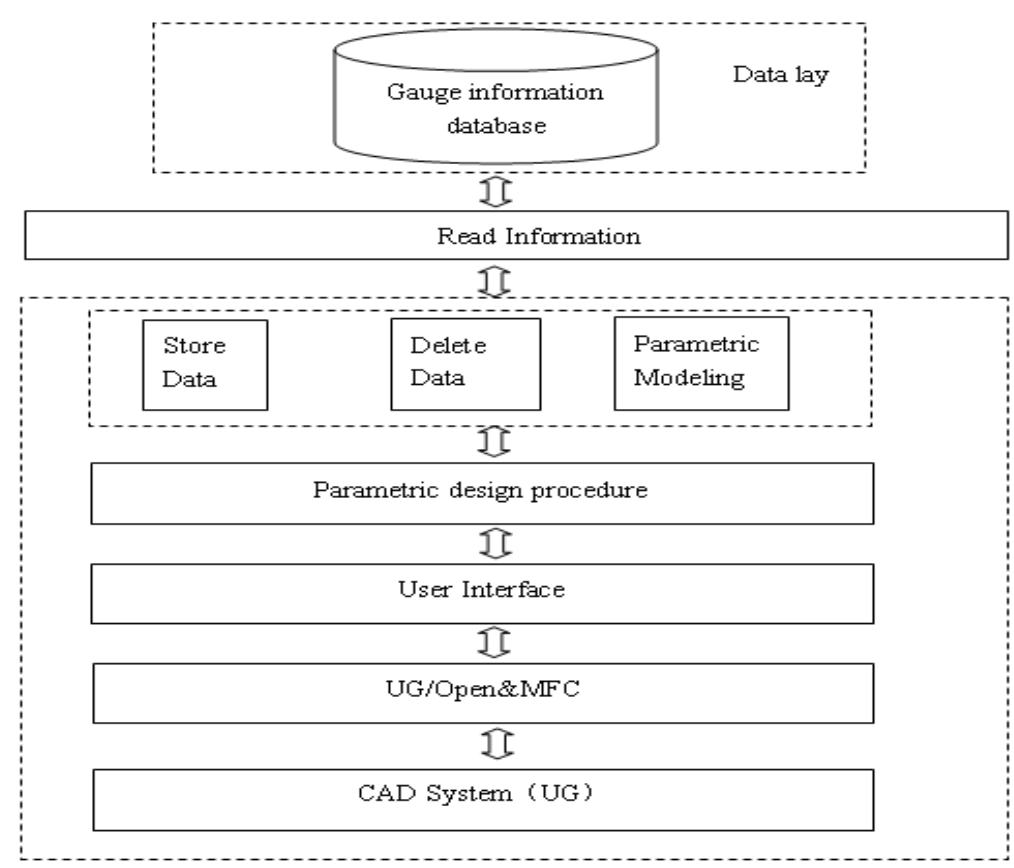

Figure 1. The overall structure of the gauge CAD system

\section{Parametric Model of the Gauge}

The plain limit gauge is a kind of the scale measuring tool. It can be "go" and "no-go" pass the workpiece method to determine whether the workpiece within the specified acceptance limits, and can not measure the actual size of the workpiece and the shape and position error values. When a hole or axis of a single feature is marked with inclusion requirements, a gauge can be used to verify it. The standard gauge is based on the Taylor principle (i.e., the principle of limit size judgment). Taylor principle provides the gauge (referred to as the general rule, with the Chinese phonetic prefix $\mathrm{T})$ should be seized with the workpiece of the prototype parts are similar, and be able to check all the size of the workpiece was seized parameters, and stop the end of the gauge $Z$ ), the individual parts of the workpiece should be inspected separately. From the point of view of interchange ability requirements, this is the most reliable, otherwise there may be errors.

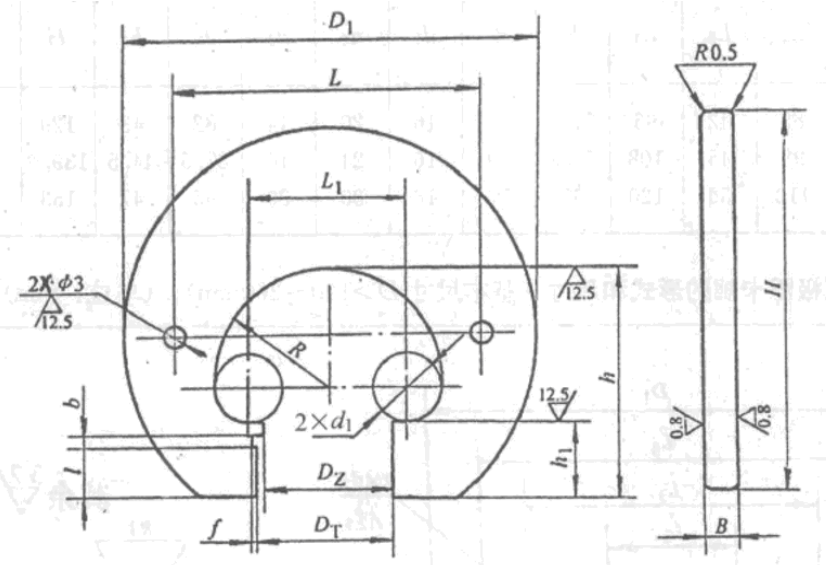

Figure 2. The parameters of Model

During the parametric modelling of the gauge, the sketch is constrained during the sketch drawing. At this time it is necessary to have a reasonable and accurate expression and to establish the relationship between parameters in order to create accurately the parameters of the model of gauge. 
First of all the main parameters need to be determined. In the rapid design process of user, the main parameters input by the user can be achieved through the dialog box in order to generate the model, and can fully control the characteristics of the model and size parameters. When the main parameters are determined, the other parameters, which can be defined as auxiliary parameters, can be determined by the main parameters calculating the expression.

Table 1.The dimension of gauge

\begin{tabular}{|c|c|c|c|c|c|c|c|c|c|c|c|c|c|}
\hline \multicolumn{2}{|c|}{ D } & \multirow{2}{*}{ D1 } & \multirow{2}{*}{$\mathrm{L}$} & \multirow{2}{*}{ L1 } & \multirow{2}{*}{$\mathrm{R}$} & \multirow{2}{*}{$\mathrm{d} 1$} & \multirow{2}{*}{1} & \multirow{2}{*}{$\mathrm{b}$} & \multirow{2}{*}{$\mathrm{f}$} & \multirow{2}{*}{$\mathrm{h}$} & \multirow{2}{*}{ h1 } & \multirow{2}{*}{ B } & \multirow{2}{*}{$\mathrm{H}$} \\
\hline from & to & & & & & & & & & & & & \\
\hline 1 & 3 & 32 & 20 & 6 & 6 & 6 & 5 & 2 & 0.5 & 19 & 10 & 3 & 31 \\
\hline 3 & 6 & 32 & 20 & 6 & 6 & 6 & 5 & 2 & 0.5 & 19 & 10 & 4 & 31 \\
\hline 6 & 10 & 40 & 26 & 9 & 8.5 & 8 & 5 & 2 & 0.5 & 22.5 & 10 & 4 & 38 \\
\hline 10 & 18 & 50 & 36 & 16 & 12.5 & 8 & 8 & 2 & 0.5 & 29 & 15 & 5 & 46 \\
\hline 18 & 30 & 65 & 48 & 26 & 18 & 10 & 8 & 2 & 0.5 & 36 & 15 & 6 & 58 \\
\hline 30 & 40 & 82 & 62 & 35 & 24 & 10 & 11 & 3 & 0.5 & 45 & 20 & 8 & 72 \\
\hline 40 & 50 & 94 & 72 & 45 & 29 & 12 & 11 & 3 & 0.5 & 50 & 20 & 8 & 82 \\
\hline 50 & 65 & 116 & 92 & 60 & 38 & 14 & 14 & 4 & 1 & 62 & 24 & 10 & 100 \\
\hline 65 & 80 & 136 & 108 & 74 & 46 & 16 & 14 & 4 & 1 & 70 & 24 & 10 & 114 \\
\hline
\end{tabular}

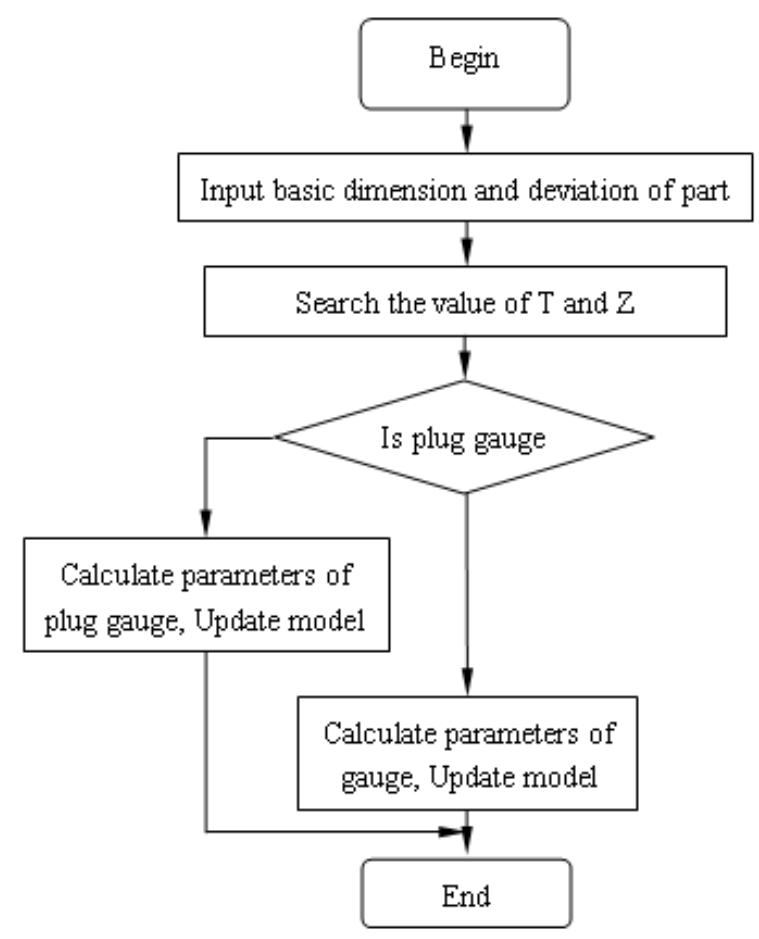

Figure 3. The flow chart of CAD system

Then, the main parameters of the input dialog box can be designed through the design of the dialog box function provided by the UG software.

After the parameter is determined, it can greatly simplify the process of parameterization design. Enter the parameter expression in the UG dialog box, which has been designed, as long as the main parameters and constant parameters can be determined to drive the other auxiliary parameters. This will be able to achieve the parametric design of the automatic calculation, and to prepare for the realization of automatic design. 


\section{Database Structure}

The gauge database contains four attributes, namely the basic dimensions and tolerance, tolerance value $\mathrm{T}$ and position elements $\mathrm{Z}$.

The gauge basic dimensions database are created according to the content of table 1.Then, using UI Open to develop the procedure in order to search the dimension of parameter model.

The tolerance database is created according to the content of table2. The procedure is developed using UI Open in order to search the tolerance of the gauge.

Then, procedure calculated the deviation of go gauge and no-go gauge can be programmed.

Upper deviation of the go gauge can be calculated by the following equation:

$$
T_{s d}=e s-Z+\frac{T}{2}
$$

Lower deviation of the go gauge can be calculated by the following equation:

$$
T_{i d}=e s-Z-\frac{T}{2}
$$

\begin{tabular}{|c|c|c|c|c|c|c|c|c|c|c|c|c|c|c|c|}
\hline \multirow{2}{*}{$\mathrm{D} / \mathrm{mm}$} & \multicolumn{3}{|l|}{ IT6 } & \multicolumn{3}{|l|}{ IT7 } & \multicolumn{3}{|l|}{ IT8 } & \multicolumn{3}{|l|}{ IT9 } & \multicolumn{3}{|l|}{ IT10 } \\
\hline & IT6 & $\mathrm{T}$ & $\mathrm{Z}$ & IT7 & $\mathrm{T}$ & $\mathrm{Z}$ & IT8 & $\mathrm{T}$ & $\mathrm{Z}$ & IT9 & $\mathrm{T}$ & $\mathrm{Z}$ & IT10 & $\mathrm{T}$ & $\mathrm{Z}$ \\
\hline to3 & 6 & 1 & 1 & 10 & 1.2 & 1.6 & 14 & 1.6 & 2 & 25 & 2 & 3 & 40 & 2.4 & 4 \\
\hline $\begin{array}{l}\text { From } 3 \text { to } \\
6\end{array}$ & 8 & 1.2 & 1.4 & 12 & 1.4 & 2 & 18 & 2 & 2.6 & 60 & 2.4 & 4 & 48 & 3 & 5 \\
\hline $\begin{array}{l}\text { From } 6 \text { to } \\
10\end{array}$ & 9 & 1.4 & 1.6 & 15 & 1.8 & 2.4 & 22 & 2.4 & 3.2 & 36 & 2.8 & 5 & 58 & 3.6 & 6 \\
\hline $\begin{array}{l}\text { From } 10 \\
\text { to } 18\end{array}$ & 11 & 1.6 & 2 & 18 & 2 & 2.8 & 27 & 2.8 & 4 & 43 & 3.4 & 6 & 70 & 4 & 8 \\
\hline $\begin{array}{l}\text { From } 18 \\
\text { to } 30\end{array}$ & 13 & 2 & 2.4 & 2 & 2.4 & 3.4 & 33 & 3.4 & 5 & 52 & 4 & 7 & 84 & 5 & 9 \\
\hline $\begin{array}{l}\text { From } 30 \\
\text { to } 50\end{array}$ & 16 & 2.4 & 2.8 & 25 & 3 & 4 & 39 & 4 & 6 & 62 & 5 & 8 & 100 & 6 & 11 \\
\hline $\begin{array}{l}\text { From } 50 \\
\text { to } 80\end{array}$ & 19 & 2.8 & 3.4 & 60 & 3.6 & 4.6 & 46 & 4.6 & 7 & 74 & 6 & 9 & 120 & 7 & 13 \\
\hline $\begin{array}{l}\text { From } 80 \\
\text { to } 120\end{array}$ & 22 & 3.2 & 3.8 & 35 & 4.2 & 5.4 & 54 & 5.4 & 8 & 87 & 7 & 10 & 140 & 8 & 15 \\
\hline $\begin{array}{l}\text { From } 120 \\
\text { to } 180\end{array}$ & 25 & 3.8 & 4.4 & 40 & 4.8 & 6 & 63 & 6 & 9 & 100 & 8 & 12 & 160 & 9 & 18 \\
\hline $\begin{array}{l}\text { From } 180 \\
\text { to } 250\end{array}$ & 29 & 4.4 & 5 & 46 & 5.4 & 7 & 72 & 7 & 10 & 115 & 9 & 14 & 185 & 10 & 20 \\
\hline $\begin{array}{l}\text { From } 250 \\
\text { to } 315\end{array}$ & 32 & 4.8 & 5.6 & 52 & 6 & 8 & 81 & 8 & 11 & 130 & 10 & 16 & 320 & 12 & 22 \\
\hline $\begin{array}{l}\text { From } 315 \\
\text { to } 400\end{array}$ & 36 & 5.4 & 6.2 & 57 & 7 & 9 & 89 & 9 & 12 & 140 & 11 & 18 & 230 & 14 & 25 \\
\hline $\begin{array}{l}\text { From } 400 \\
\text { to } 500\end{array}$ & 40 & 6 & 7 & 63 & 8 & 10 & 97 & 10 & 14 & 155 & 12 & 20 & 250 & 16 & 28 \\
\hline
\end{tabular}

Table 2. The work of IT6-IT10 gauge manufacturing tolerances and position factor value

Upper deviation of the no-go gauge can be calculated by the following equation: 


$$
Z_{s d}=e i+T
$$

Lower deviation of the no-go gauge can be calculated by the following equation:

$$
Z_{i d}=e i
$$

\section{Conclusion}

According to the above content, the CAD system has been developed by the development platform of Visual C++ 6.0 on the environment of UG NX 6.0.

For the convenience of users, the UG Menu has been created by the .men file, which is saved in the directory startup valued the environment variable UGII_USER_DIR.

The .men content is

VERSION 120

EDIT UG_GATEWAY_MAIN_MENUBAR

AFTER UG_APPLICATION

CASCADE_BUTTON LG_menu_prt

LABEL DESIGN GAUGE

END_OF_AFTER

MENU LG_menu_prt

BUTTON LG

LABEL PLUG

ACTIONS LG.dlg

BUTTON kg

ACTIONS kg.dlg

BUTTON TOOL_DESIGN

LABEL GAUGE

ACTIONS kg.dlg

BUTTON TOOL_DESIGN

LABEL CAD

ACTIONS ToolDesign

BUTTON TOOL_INFO

LABEL INFO MANAGEMENT

ACTIONS ToolInfo

END_OF_MENU

The generate $3 \mathrm{D}$ model is shown in figure 4 .

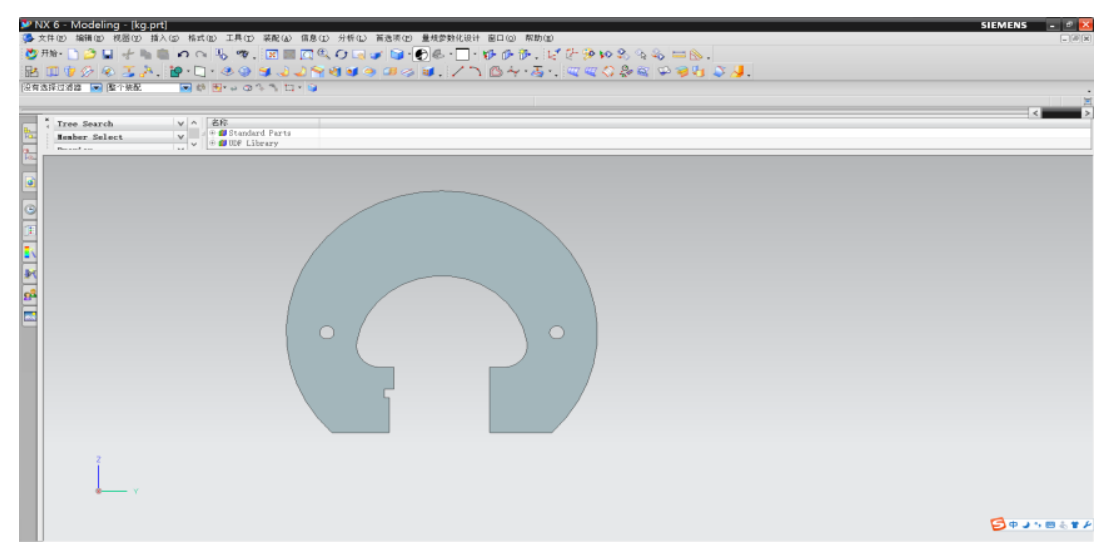

Figure 4. The 3D model of CAD system

The generate $2 \mathrm{D}$ drawing is shown in figure 5 . 


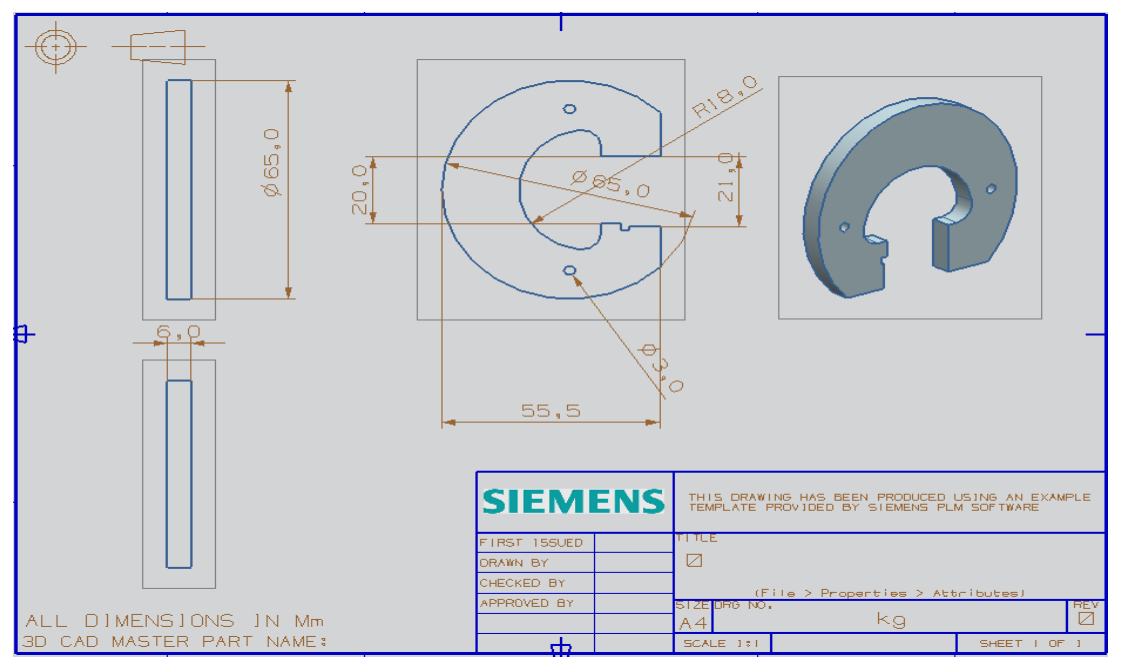

Figure 5. The 2D drawing of CAD system

Using the method provided in this paper, the rapid design of the gauge can realize, which laid the foundation for the design of the automatic measuring tool.

\section{Acknowledgment}

This Project is supported by the National Science Foundation for Distinguished Young Scholars of China (Grant No.51505336), and National Science Foundation for Young Scholars of Tianjin (Grant No.15JCQNJC05200).

\section{References}

1. Douglas Singleton, Akira Kato. Yoshida Gauge procedure with gauge fields of various ranks. Physics Letters A,E326-337,335(2004)

2. Huang Yong. Examples of the development for UG Open API, MFC\&COM(National Defense Industry Press,2009)

3. Wu Haihua. The Design of CAD System for Precision Smooth Limit Gauges. Metrology and testing technology,E6-8,2(2002)

4. Dong Junli.. Computer Aided Design of Smooth Limit Gauges. Journal of Liaoning Teachers College,E90,5(2003)

5. Su Guisheng. Computer Aided Design of Smooth Limit Gauge Based on AutoCAD. Tool technology . 8 (2003) 